\title{
Experimental and Numerical Study of an Automotive Component Produced with Innovative Ceramic Core in High Pressure Die Casting (HPDC)
}

\author{
Giovanna Cornacchia ${ }^{1, *}$, Daniele Dioni ${ }^{1}$, Michela Faccoli ${ }^{1}{ }^{1}$, , Claudio Gislon ${ }^{2}$, Luigi Solazzi ${ }^{1}$, \\ Andrea Panvini ${ }^{1}$ and Silvia Cecchel ${ }^{1}$ (D) \\ 1 DIMI, Department of Industrial and Mechanical Engineering, University of Brescia, via Branze 38, \\ 25123 Brescia, Italy; daniele.dioni@gmail.com (D.D.); michela.faccoli@unibs.it (M.F.); \\ luigi.solazzi@unibs.it (L.S.); a.panvini@piq2.com (A.P.); s.cecchel@unibs.it (S.C.) \\ 2 Co.Stamp. s.r.l. Via Verdi 6, 23844 Sirone (LC), Italy; claudio.gislon@costampgroup.it \\ * Correspondence: giovanna.cornacchia@unibs.it; Tel.: +39-030-371-5827; Fax: +39-030-370-2448
}

Received: 14 December 2018; Accepted: 8 February 2019; Published: 12 February 2019

\begin{abstract}
Weight reduction and material substitution are increasing trends in the automotive industry. High pressure die casting (HPDC) is the conventional casting technology for the high volume production of light alloys; it has recently found wide application in the manufacturing of critical components, such as complex and thin geometry automotive parts. However, the major restriction of this affordable technology is the difficulty to design and realize hollow sections or components with undercuts. An innovative way to further increase the competitiveness of HPDC is to form complex undercut shaped parts through the use of new lost cores that are able endure the high pressures used in HPDC. This paper investigates the use of innovative ceramic lost cores in the production of a passenger car aluminum crossbeam by HPDC. Firstly, process and structural simulations were performed to improve the crossbeam design and check the technology features. The results led to the selection of the process parameters and the production of some prototypes that were finally characterized. These analyses demonstrate the feasibility of the production of hollow components by HPDC using ceramic cores.
\end{abstract}

Keywords: non-ferrous alloys; ceramic core; FEA; HPDC; de-coring; material characterization

\section{Introduction}

The current use of castings for aluminum chassis structural applications is limited to a niche market for high performance cars. Nevertheless, automobile weight reduction is currently becoming an essential requirement to improve vehicle performance [1] and reduce fuel consumption and harmful emissions [2-7]. The environmental importance of reducing the weight of these aluminum components has been recently demonstrated by means of a life cycle assessment tool [8-10]. The studies considered all the component life-related phases (mineral extraction, component manufacturing, use on a vehicle, and end of life), demonstrating the relevant contribution of their reduced weight to the reduction of pollutant emission during vehicle circulation. Therefore, the application of lightweight metal castings for the production of low range and high volume automotive components is increasing, not only for chassis, but also engine blocks, cylinder heads, intake manifolds, brackets, housings, transmission parts, and suspension systems [2,7-14].

Of course, the preservation of compliance with the safety and performance levels required by automotive standards is paramount $[5,15]$. This is particularly true for safety-relevant automotive products (i.e., crossbeams, control arms, etc.), which are defined as "reliable in regard to safety-relevant 
defects". Indeed, the necessity of excellent cast integrity requires the use of high cost and/or low productivity technologies, such as gravity casting or high vacuum die casting [2,16-19]. From a mechanical and structural point of view, gravity casting technology guarantees excellent performances, but it is not suitable for large volumes because the slow production cycle and component feasibility still limit the possibility of reducing the thickness to less than $3.5 \mathrm{~mm}$ [20-26].

In this context, a consolidated and promising technology is certainly high pressure die casting (HPDC). HPDC is a very competitive technology for high production volumes, low costs, near-net shape parts, and the opportunity to produce thin components. The main limit of HPDC technology is related to part design limitations associated with the difficulty of using lost cores, which are the only way to form complex undercut shaped parts. Indeed, the lost cores made of traditional gravity technology materials can only be utilized when the process pressure is a few bars because they are not compatible with the high hydrostatic pressure and also when the flow speed is much lower than the high flow speed involved in HPDC process. Traditionally, metallic moving cores are used when HPDC parts have undercuts. The metallic moving core, in contrast with the lost core, is a permanent mold technology [22-24]. It means that, currently, the design of HPDC hollow section has to take into account the ejection of the metallic moving core [25-30]. This limits the feasibility of automotive components with complex closed-profile sections, which offer higher torsional stiffness and a further weight reduction $[5,6]$ and, consequently, have become more and more required in the transport field.

For all these reasons, the desire to extend HPDC to automotive components has encouraged numerous studies aimed to obtain HPDC-resistant cores. The main requirements of these lost cores are related to resistance at standard HPDC conditions, and can be broken down into mechanical properties and process reliability. As regards their mechanical properties, the principal characteristics are high Young's modulus and adequate bending and compression strengths. As regards process reliability, it is indispensable for achieving shape stability, dimensional accuracy, surface quality, thermal shock resistance, possibility of complex shapes and easy, clean removability. Different types of soluble cores have been developed in recent years [31-37].

Numerous researches have proposed many kinds of new collapsible or expendable cores comprised of sand, salt, and metallic and organic material [38-42].

In particular, the use of salt cores, already known in gravity or low pressure casting processes, has received extended attention for HPDC [39-42]. Yaokawa et al. [39] investigated the strength of four binary systems, sodium chloride-sodium carbonate, potassium chloride-potassium carbonate, potassium chloride-sodium chloride, and potassium carbonate-sodium carbonate, whose liquidus temperature is fit for use in the HPDC processing of aluminum alloys. Interesting studies on the use of lost cores made from salt (sodium chloride) were performed by Fuchs et al. [41,42]. The authors compared numerical simulation results with corresponding experiments to predict core failure during the casting process. As a result, they obtained process parameters for the successful use of this salt cores in HPDC.

Various patents have been applied for in this regard [43-48], such as for the production of aluminum closed deck cylinder blocks by HPDC [43] or aluminum based engine blocks [44]. Brown et al. [45] disclosed novel water-soluble cores for metal casting use and methods for making such cores. The cores essentially consist of a water-soluble salt and a synthetic resin. Although the literature confirms the above-reported potential for HPDC salt cores, their application for demanding automotive conditions needs additional research to reach the high strength required.

These problems were recently addressed by studing a new type of core, more precisely, an HPDC ceramic core. The choice of ceramic material is related to the use of injection molding, necessary for complex core shapes production. This technology provides good dimensional tolerance and low roughness for the internal component cavity surface. In addition, ceramic material without binder does not release gas during the casting and would consequently guarantee higher mechanical properties $[49,50]$. 
Regarding the decoring, although both leaching and high pressure water jet techniques can be easily applied for ceramic core removing, it is necessary to highlight the possible difficulty of accessing complex cavities, coupled with the particular resistance of this kind of core. This ceramic core would resist to over 1000 bar, compatible with HPDC process, instead of the maximum 2 bar of the traditional lost cores. The most relevant benefits expected from this application are reduction of machining processes, decreased production times, increased torsional stiffness, and reduction of weight.

It is against this background that the aim of this project should be seen: the study, development, and industrialisation of a new method, which uses this new ceramic core applied to HPDC. This implementation not only allows the production of a lighter and improved safety-relevant automotive component, but permits achievement of relevant benefits in comparison with both conventional die with moving cores and components made of bulk closed sections.

In this project, the feasibility study on the production of crossbeams using this innovative lost ceramic core in HPDC has demonstrated that this new type of core may contribute to making HPDC competitive with respect to the conventional casting process for the production of automotive hollow parts. The specific goal of this paper is to re-design, produce, and demonstrate the feasibility of a new, one-piece hollow aluminum crossbeam for passenger cars produced with HPDC and ceramic cores.

This paper firstly shows the results of process and structural simulations used for the selection of the most proper feature of the crossbeam. Computer aided engineering (CAE) simulation of the HPDC process was used to forecast and improve the quality of the casting and verify foundry feasibility, and finite element method (FEM) analysis was used to evaluate part performances and improve the design. Foundry process simulation has been a well-known and widely used tool for more than twenty years for improving die and process design, in order to achieve better part quality.

These investigations, supported by the experimental characterization of the ceramic cores, allowed the definition of the component geometry and the selection of the most proper materials and process parameters for the production of some crossbeam prototypes. Finally, hardness measurements and microstructural analyses were carried out on these prototypes.

\section{Materials and Methods}

\subsection{Description of the Automotive Component Structure and Materials}

\subsubsection{Geometric Description}

The front crossbeam is a functional, structural, and safety vehicle component that acts as a link between the suspension elements, the steering knuckles, and the main frame. Due to the high mechanical resistance required, the crossbeam of a medium-size car is traditionally produced in iron castings or trimmed and folded steel sheets.

In some recent applications [7], these heavy metals solutions were substituted by re-designed aluminum alloys parts produced with different casting technologies (i.e., HPDC) in order to reduce the weight. As stated in the Introduction section, the shape of the casting must be designed taking into account the technological limitations of HPDC, among which the most restrictive are the casting ejection from a rigid steel die and the limited number of small undercuts, which can only be managed with sliding cores.

Starting from these considerations, the new expendable ceramic core technology was applied to optimize the shape of an aluminum HPDC crossbeam in order to further reduce weight and increase stiffness. The design of either the traditional HPDC crossbeam or the modified one can be observed in Figure 1. It is worthwhile to note that the main dimensions and the material (aluminum alloy EN AC-43500) of the modified crossbeam and the original crossbeam are the same. In the new design, the central area of the component was closed to form a box section, whereas the extremities were not modified because they constitute the main connection areas with the other suspension elements and their interfaces could not be moved. 
The original open profile design, sketched in Figure 1a, was modified as shown in Figure 1b, where the reinforcement ribs on the external surface, no longer necessary, were removed. The final shape of the hollow cavity is shown in Figure 2a through the expendable ceramic core that creates the cavity. In addition, in Figure $2 b$, it is possible to observe the geometry and the positioning solutions in the mold cavity adopted for the ceramic core. The introduction of the new ceramic core technology and the applied design modifications led to a final weight of $3.93 \mathrm{~kg}$ for the boxed part as compared to $3.95 \mathrm{~kg}$ for the traditional HPDC one.

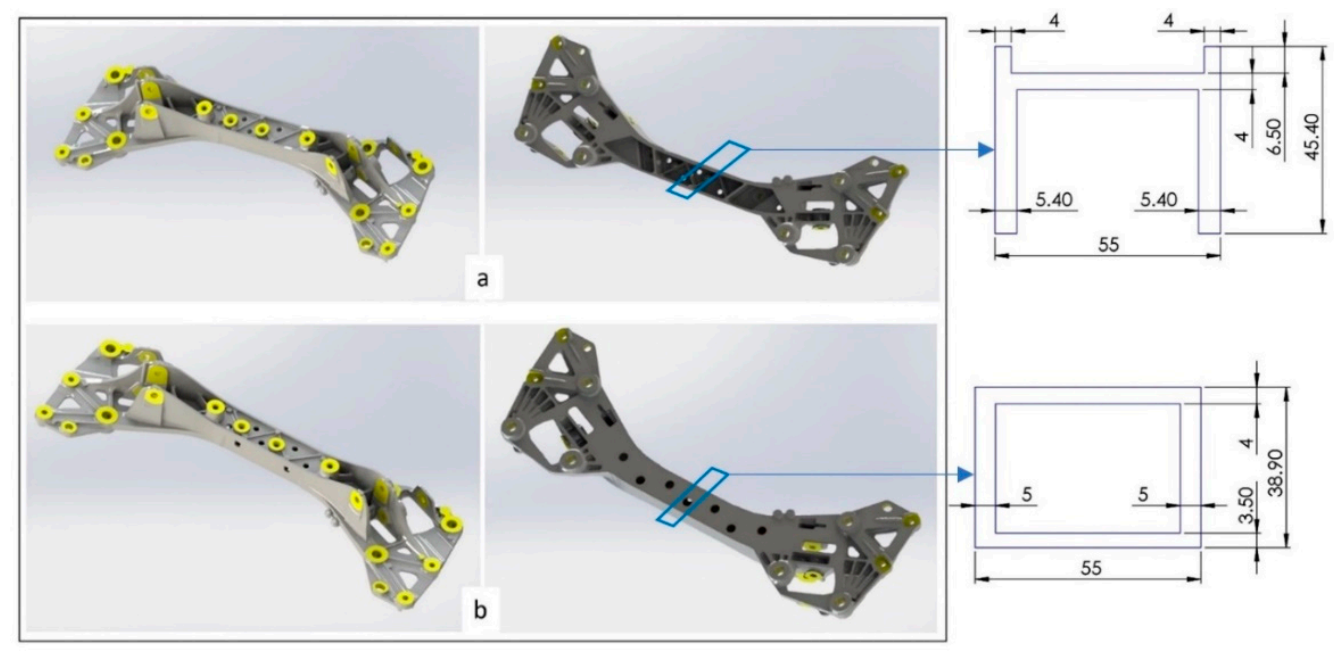

Figure 1. 3D design and schematic sketch of the section profile of (a) original crossbeam (b) modified crossbeam. The dimensions are expressed in (mm).

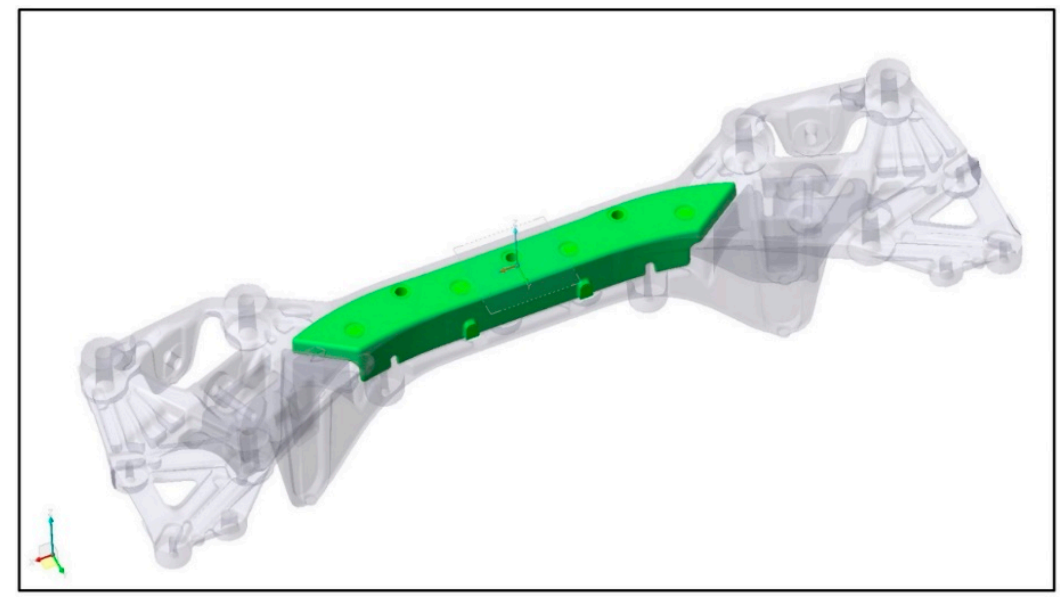

(a)

Figure 2. Cont. 


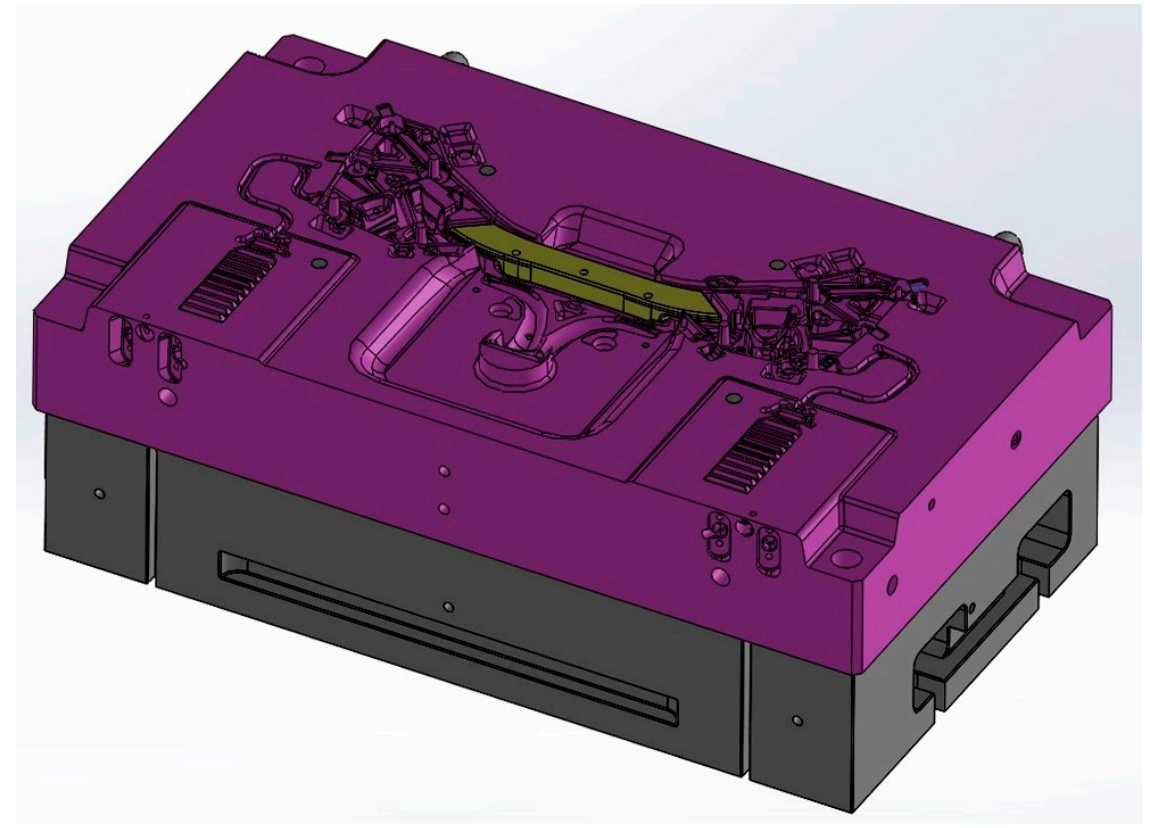

(b)

Figure 2. (a) 3D model of the closed profile crossbeam with ceramic core. (b) The geometry and the positioning solutions in the mold cavity adopted for the ceramic core.

\subsubsection{Material Properties}

The materials analyzed for the selection of the core's features are $\mathrm{Al}_{2} \mathrm{O}_{3}+\mathrm{SiO}_{2}+\mathrm{K}_{2} \mathrm{O}$ ceramic samples, characterized by different percentages of these oxides. More details can be found in $[49,50]$. Three different sets of samples (hereafter named "a", "b", and "c"), with dimensions of $11 \times 11 \times 300 \mathrm{~mm}^{3}$ for samples "a" and $6 \times 8 \times 85 \mathrm{~mm}^{3}$ for samples " $\mathrm{b}$ " and " $\mathrm{c}$ ", were industrially produced and analyzed. Different sintering temperatures were considered for samples "a", " $\mathrm{b}$ ", and " $\mathrm{c}$ ": $\mathrm{T}=892,900$, and $908^{\circ} \mathrm{C}$ (specimens "a"), and $\mathrm{T}=1075$ and $1110^{\circ} \mathrm{C}$ (specimens " $\mathrm{b}$ " and " $c$ ", respectively). The properties of these samples will be analyzed as detailed in the following section. After that, the hollowed aluminum high pressure die casting crossbeam prototypes made of EN AC-43500 aluminum were produced. Table 1 shows the chemical composition ranges for the alloy used.

Table 1. Chemical composition of EN AC-43500 aluminum alloy.

\begin{tabular}{cccccccccc}
\hline Chemical Elements & $\mathbf{S i}$ & $\mathrm{Fe}$ & $\mathbf{C u}$ & $\mathbf{M n}$ & $\mathbf{M g}$ & $\mathbf{N i}$ & $\mathrm{Zn}$ & $\mathrm{Sn}$ & $\mathrm{Ti}$ \\
\hline EN AC-43500 & $9.5-11.5$ & 0.15 & 0.03 & $0.5-0.8$ & $0.1-0.5$ & - & 0.07 & - & 0.15 \\
\hline
\end{tabular}

\subsection{Experimental and Numerical Setups}

\subsubsection{FEA}

Structural Simulation

A necessary premise for this section is that the evaluation of the original structural performances is only feasible when the real crossbeam load conditions are known, and these depend on several factors, such as type of car, frame position, bounded component loads, and standard vehicle use (straight road, curves, etc.). These loading conditions are confidential data and, therefore, cannot be disclosed; for this reason, this experimental research was developed considering dummy loads, based on field experience. 
Notwithstanding this limit, it is important to underline that careful comparative work between the original structural solution and the new modified one was performed. Due to the complex geometry of the component, an analytical study can be implemented only for estimating the real mechanical behavior and for a preliminary sizing of the boxed solution geometry.

The numerical analyses were carried out through Autodesk Simulation ${ }^{\circledR}$ software. The finite element models employed for both geometries are composed of parabolic brick elements. The finite element model for the original geometry is composed of about $1.4 \times 10^{6}$ degrees of freedom, $2.9 \times 10^{5}$ elements, and $4.5 \times 10^{5}$ nodes, whereas the finite element model for the modified geometry is constituted of about $1.6 \times 10^{6}$ degrees of freedom, $3.1 \times 10^{5}$ elements, and $4.7 \times 10^{5}$ nodes. All analyses were performed considering the material in linear elastic field. Several component simulations were conducted both in the original and in the boxed configuration to compare their mechanical behavior.

The aim of the first numerical analyses is to evaluate the dynamic performance of the components. This element is manufactured for a specific vehicle and it is very important to know the values of the first natural frequencies and relative vibration modes. Moreover, as mentioned above, the stiffness of the boundary conditions is unknown, so two different simulations have been carried out to fill this gap, the first with free-free boundary conditions, and the second with rigid constraints in the component fixing points. These two boundary hypotheses constitute the opposite extreme fixing conditions of the crossbeam during its lifespan. In addition to the modal studies, buckling analyses were performed to evaluate and compare the load capacity of the two different types of components [51-53].

The analyses were conducted with two different external loads. In the first load condition, two forces (each with a value of 100,000 N) were applied to the component, whereas, in the second load condition, two moments (each with a value of $10,000 \mathrm{~N} \cdot \mathrm{m}$ ) were imposed with the same direction of the main axis of the component. The selected load conditions allow for comparison of the mechanical behavior of the two different crossbeam geometries. The magnitude, type, and direction of the external load were carefully selected, based on previous experience, in order to perform a comparative analysis with different load buckling factor values. Figure 3 shows the buckling analysis model considered, while Table 2 indicates the FEM simulation parameters used.

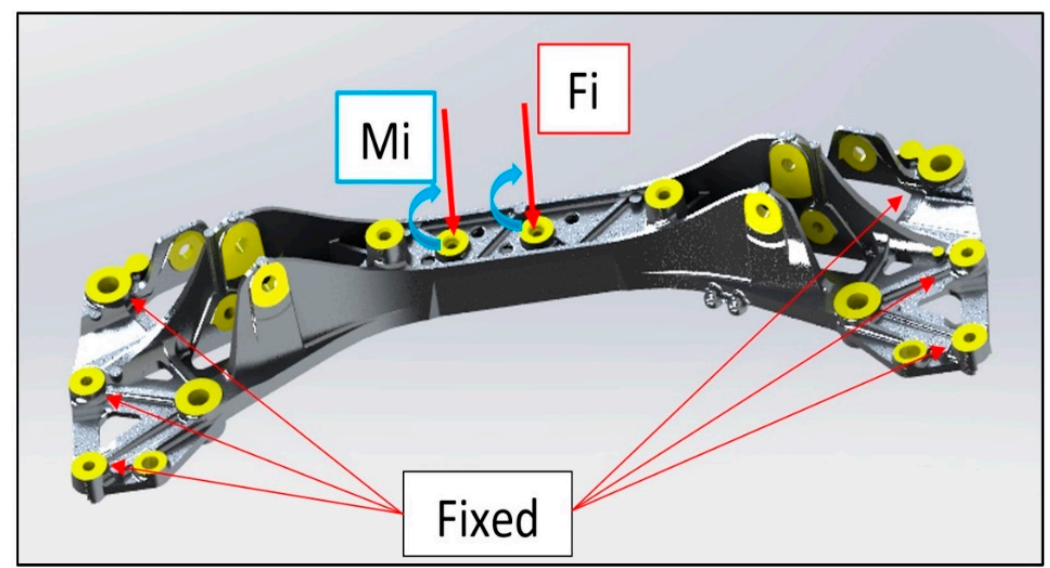

Figure 3. Buckling analysis model: boundary condition and load cases.

Table 2. FEM simulation parameters.

\begin{tabular}{cccc}
\hline $\begin{array}{c}\mathrm{E} \text { (Young Modulus) } \\
\left(\mathbf{N} / \mathbf{m m}^{2}\right)\end{array}$ & $\begin{array}{c}v \text { (Poisson } \\
\text { Coefficient) }\end{array}$ & $\begin{array}{c}\text { G (Tangential Modulus) } \\
\left(\mathbf{N} / \mathbf{m m}^{2}\right)\end{array}$ & $\begin{array}{c}\rho \text { (Density) } \\
\left(\mathbf{k g} / \mathbf{d m}^{\mathbf{3}}\right)\end{array}$ \\
\hline 70,000 & 0.3 & 30,000 & 2.7 \\
\hline
\end{tabular}

Process Simulation

Computer aided engineering (CAE) HPDC process simulations were used to forecast and improve the quality of the casting and verify foundry feasibility. In particular, these simulations were useful 
in the design phase to prevent foundry defect formation (shrinkage porosity, air entrainment, etc.) by changes in the component shape, to guide the die design, leading to the final set of process boundary conditions.

These analyses were carried out with CastleBody from PiQ2 [54,55]. This is a new generation dual phase casting simulation software that can handle both fluids and the spraying phenomena, thanks to a compressible-incompressible dual phase volume of fluid (VOF) formulation. In most simulation software, air is not considered as a moving fluid but only as a steady (not moving) computational domain, and pressure is calculated according to a volume ratio that changes during filling, but no outflow can be modeled. This is a relevant item since, in a foundry process, the filling of a die usually involves two fluids: the molten metal entering into the cavity and the air that is displaced and must exit from it. Their interaction should be carefully analyzed since the pressure increase that develops while filling in the empty mold space due to gas compression leads to partial venting of the air, from the die, through air vents and outflows. Consequently, these analyses are also useful in order to comprehensively evaluate the way air outlets are designed and located.

From the solidification point of view, a potential problem in the production of HPDC castings with disposable ceramic cores could be their different thermal properties compared to the hot work tool steel W1.2343, usually used for the other parts of the die. This issue was faced by modeling the actual thermal properties (temperature, conductivity, and specific heat) of the ceramic core during both filling and solidification calculations, in order to take into account this difference in terms of both flow and shrinkage porosity prediction. Due to its low conductivity, neglecting the heating of the core during the first seconds after it is placed into the mold, the initial ceramic insert temperature was set to the preheating value of $100^{\circ} \mathrm{C}$. A uniform steel temperature of $230^{\circ} \mathrm{C}$ was set for the die according to the average value measured on the actual die. The pouring temperature of the liquid alloy was set at $690^{\circ} \mathrm{C}$. The thermal properties of the materials used in the simulation are shown in Table 3, while the the CFD simulation parameters are shown in Table 4.

Table 3. Thermal properties of mold materials.

\begin{tabular}{cccc}
\hline \multicolumn{4}{c}{ Ceramic insert } \\
\hline $\begin{array}{c}\text { Thermal Conductivity } \\
(\mathrm{W} / \mathrm{m} / \mathrm{K})\end{array}$ & $\begin{array}{c}\text { Specific Heat } \\
\left(\mathrm{m}^{2} / \mathrm{s}^{2} / \mathrm{K}\right)\end{array}$ & $\begin{array}{c}\text { Density } \\
\left(\mathbf{k g} / \mathrm{m}^{3}\right)\end{array}$ & $\begin{array}{c}\text { Initial Temperature } \\
\left({ }^{\circ} \mathrm{C}\right)\end{array}$ \\
\hline 0.336 & 818.3 & 1920 & 100 \\
\hline $\begin{array}{c}\text { Thermal Conductivity } \\
(\mathrm{W} / \mathrm{m} / \mathrm{K})\end{array}$ & $\begin{array}{c}\text { Specific Heat } \\
\left(\mathrm{m}^{2} / \mathrm{s}^{2} / \mathrm{K}\right)\end{array}$ & $\begin{array}{c}\text { Density } \\
\left(\mathbf{k g} / \mathrm{m}^{3}\right)\end{array}$ & $\begin{array}{c}\text { Initial Temperature } \\
\left({ }^{\circ} \mathrm{C}\right)\end{array}$ \\
\hline 28.6 & 460 & 7780 & 230 \\
\hline
\end{tabular}

Table 4. CFD simulation parameters.

\begin{tabular}{cc}
\hline Pouring temperature of liquid alloy & $690{ }^{\circ} \mathrm{C}$ \\
\hline Ceramic insert preheating temperature & $100{ }^{\circ} \mathrm{C}$ \\
\hline Initial temperature of the die & $230{ }^{\circ} \mathrm{C}$ \\
\hline Heat transfer coefficient between liquid Al and mold during filling & $4000 \mathrm{~W} / \mathrm{m}^{2} / \mathrm{K}$ \\
\hline Heat transfer coefficient between liquid Al and mold during solidification & $1200 \mathrm{~W} / \mathrm{m}^{2} / \mathrm{K}$ \\
\hline Slow shot plunger speed & $0.18 \mathrm{~m} / \mathrm{s}$ \\
\hline Fast shot plunger speed & $3.5 \mathrm{~m} / \mathrm{s}$ \\
\hline Third phase intensified pressure on metal & $90 \mathrm{MPa}$ \\
\hline Shotsleeve active length & $0.860 \mathrm{~m}$ \\
\hline Fast shot start stroke & $0.563 \mathrm{~m}$ \\
\hline
\end{tabular}


The heat transfer coefficient between the alloy and steel during filling was set at $4000 \mathrm{~W} / \mathrm{m}^{2} \mathrm{~K}$. Both standard and ceramic cored versions of the casting were simulated in order to understand the difference in filling, improve the runners and gating layout for both configurations, and check for filling- or solidification-related defect formation.

According to well-known die design and process parameters calculation guidelines [56], the gate size was calculated so as to avoid excessive metal velocities $(>40 \mathrm{~m} / \mathrm{s})$ at the gate, in order to reduce the risk of ceramic insert erosion or die soldering while allowing a fast-enough filling time to avoid filling-related defects. Optimal injection parameters (plunger strokes and velocities) for the simulation were set according to theoretical calculations on filling to achieve a suitable filling time of about $75 \mathrm{~ms}$, typical for the average $3.5-5 \mathrm{~mm}$ thickness range of the part [56]. According to that, a first phase slow shot speed of $0.18 \mathrm{~m} / \mathrm{s}$ and a second phase fast shot speed of $3.5 \mathrm{~m} / \mathrm{s}$ were adopted. The commutation between slow and fast shot was set so that fast shot velocity would be fully developed when metal reached the gate. A final third phase intensified pressure on the metal by $90 \mathrm{MPa}$, typical for not-crash-relevant structural parts imposed on the solidifying alloy to eliminate or reduce shrinkage defects. Simulations were run on a prevalent hexahedral conformal mesh of about 1,000,000 cells. Local mesh refinement near high speed flow sensitive regions (runners and overflow gatings, thinner sections) was adopted in order to achieve a better flow pattern representation, as shown in Figure 4.

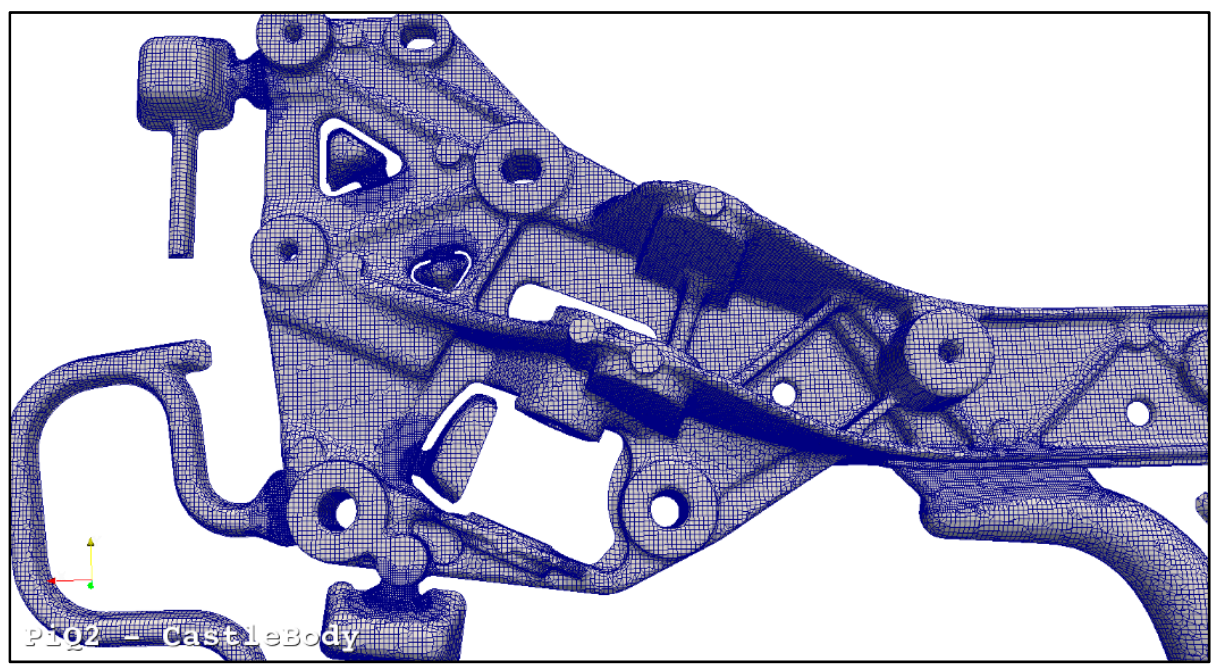

Figure 4. Local mesh refinement.

\subsubsection{Material Characterization}

\section{Ceramic Samples}

The selected ceramic cores were experimentally characterized in terms of:

- Density

For each material, cubic samples having a volume of about $1 \mathrm{~mm}^{3}$ were cut from the industrially produced bars described in the "Materials and Methods" section. A pycnometer carefully filled with ethanol absolute at ambient temperature was used, and the density was calculated according to Equation (1):

$$
\rho_{\text {ceramic }}=\rho_{\text {ethanol }} \cdot \frac{\left(m_{1}\right)}{\left(m_{1}+m_{2}-m_{3}\right)},
$$

where

$\rho_{\text {ethanol }}=0.79(\mathrm{~g} / \mathrm{mL})$;

$m_{1}=$ dry sample weight $(\mathrm{g})$;

$m_{2}=$ pycnometer fill with ethanol weight $(\mathrm{g})$; 
$m_{3}=$ pycnometer fill with ethanol + samples weight $(\mathrm{g})$.

- Ceramic Decoring

High pressure water jet technique and different leaching tests were conducted in order to select the proper method for the removal of the ceramic core from the aluminum component. In particular, this latest activity started with the evaluation of the effect of different acids on both ceramic and aluminum samples. Indeed, the leaching method has to be effective only on the core, maintaining an unchanged metal structure. For each selected material, ceramic cubic samples having a volume of about $1 \mathrm{~mm}^{3}$ were cut from the industrially produced bars. Aluminum samples were considered likewise. Samples were pickled for 1 hour in different distilled water solutions with the following substances: $5 \%$ and $10 \% \mathrm{HF} ; 65 \% \mathrm{HNO}_{3} ; 50 \% \mathrm{C}_{6} \mathrm{H}_{8} \mathrm{O}_{7} ; 50 \% \mathrm{CH}_{3} \mathrm{COOH} ; 50 \%$ and $100 \% \mathrm{C}_{6} \mathrm{H}_{8} \mathrm{O}_{7}+$ $\mathrm{CH}_{3} \mathrm{COOH}$ (1:1). Finally, the specimens were rinsed in water and dried. The specimens were weighed before and after the tests and the mass loss was determined.

\section{- Three-Point Bending Test}

The bending test is one of the most common methods to study the mechanical behavior of brittle ceramic. A three-point bending test was used to determine the flexural strength $\sigma_{\mathrm{f}}(\mathrm{MPa})$ and the Young Modulus E (GPa), according to UNI EN 843:1 [57] and UNI EN 843:3 [58], respectively. The samples were first dried in a laboratory oven at $\mathrm{T}=60^{\circ} \mathrm{C}$ for $30 \mathrm{~min}$ in order to remove potential moisture that can affect mechanical properties. The experimental setup includes the bending device and an electromechanical Instron 3369 testing machine with a $50 \mathrm{kN}$ loading cell. A constant crosshead displacement speed of $0.5 \mathrm{~mm} / \mathrm{min}$ was employed. The pins' diameter was $10 \mathrm{~mm}$, and their span " $\mathrm{L}$ " was $80 \mathrm{~mm}$ for material "a" and $60 \mathrm{~mm}$ for materials " $\mathrm{b}$ " and "c", selected on the basis of specimen dimension. The flexural strength of (MPa) was calculated according to Equation (2) [57]:

$$
\sigma_{f}[\mathrm{MPa}]=\frac{3 F_{\max } L}{2 b h^{2}}
$$

where

$F_{\max }[\mathrm{N}]=$ maximum load;

$b[\mathrm{~mm}]=$ sample width, corresponding to the side of the bar orthogonal to the direction of the load; $h[\mathrm{~mm}]=$ sample thickness.

The test for the calculation of the Young modulus (according to Equation (3) [58]) consists in six loading and unloading cycles from $0 \mathrm{~N}$ to a load $F \leq F_{r}$, where $F_{r}$ is the load at break obtained from the flexural strength tests. The same cycles were replicated on a reference steel bar sized $15 \times 11 \times 130 \mathrm{~mm}^{3}$.

$$
E_{i}[M P a]=\frac{\left(F_{2}-F_{1}\right) L^{3}}{4 b h^{3}\left(d_{c}-d_{s}\right)}
$$

where

$F_{1}[\mathrm{~N}]=10 \% F_{\max } ;$

$F_{2}[\mathrm{~N}]=90 \% F_{\max } ;$

$L[\mathrm{~mm}]=$ pin span;

$b[\mathrm{~mm}]=$ sample width;

$h[\mathrm{~mm}]=$ sample thickness;

$d_{c}[\mathrm{~mm}]=$ sample displacement, in the range between $F_{1}$ and $F_{2} ;$

$d_{s}[\mathrm{~mm}]=$ reference steel bar displacement, in the range between $F_{1}$ and $F_{2}$.

Hollowed Aluminum High Pressure Die Casting Component

The prototypes were experimentally characterized in terms of:

\section{- Microstructure}


Transverse sections of the hollowed component in the as-cast condition were obtained for microstructural characterization. They were wet-ground through successive grades of $\mathrm{SiC}$ abrasive papers from P120 to P1200, followed by diamond finishing to $0.1 \mu \mathrm{m}$. The samples were examined using optical microscopy (OM) using a Leica DMI 5000M (Leica Microsystem, Milan, Italy) and scanning electron microscopy (SEM) using a LEO EVO 40 (Zeiss, Milan, Italy). Semiquantitative chemical analyses were obtained by means of an Energy Dispersive Spectroscopy (EDS)-Link Analytical eXL probe (Oxford Instruments, Milan, Italy), with a spatial resolution of a few microns.

\section{- Hardness}

Vickers microhardness (HV) tests were carried out on a transverse section of the hollowed component under $2.94 \mathrm{~N}$ (0.3 kgf) load applied for $15 \mathrm{~s}$, by means of a Micro Duromat 4000 Reichert Jung instrument, according to ASTM E92-16 and ASTM E140-02. The most proper method to assess the resistance of this component is micr-hardness. Indeed, tensile specimens cannot be machined from the component due to its geometry. In addition, the hardness profile would provide information about the overall mechanical properties along the entire cross-section, highlighting eventual local instability. These hardness gradients could be related both to the potential presence of defects typical of casting (i.e., porosities), and to possible effects at the interface between the ceramic core and the aluminum component.

\section{Results and Discussion}

\subsection{FEA Results}

\subsubsection{Mechanical Behaviour Simulation}

The results of the component displacement with respect to the two different boundary conditions applied in the finite element model (free-free and fixed) are reported in Figures 5 and 6.

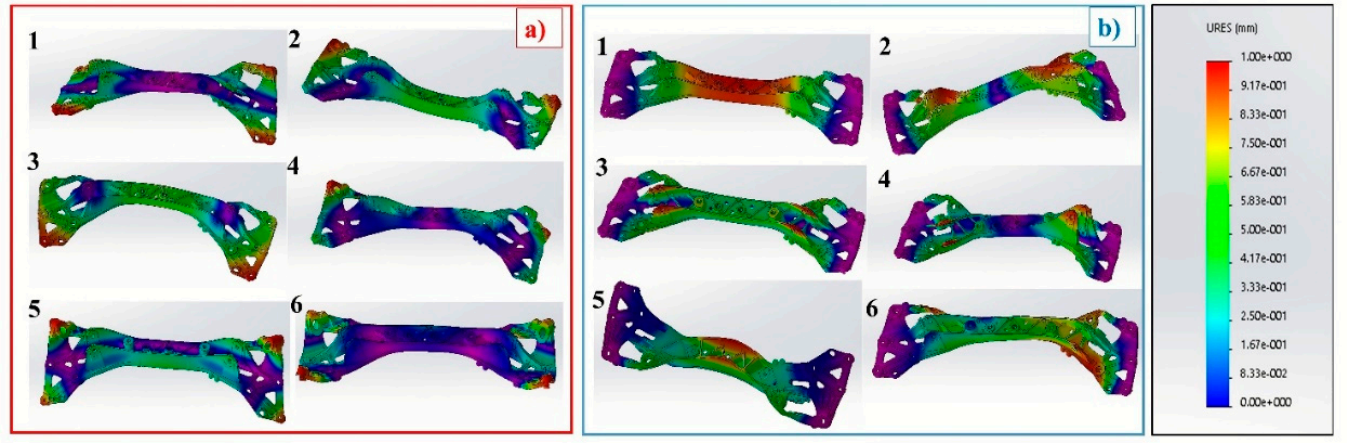

Figure 5. Displacement trend for the first six vibration modes for original geometry: (a) free-free boundary conditions and (b) fixed conditions.
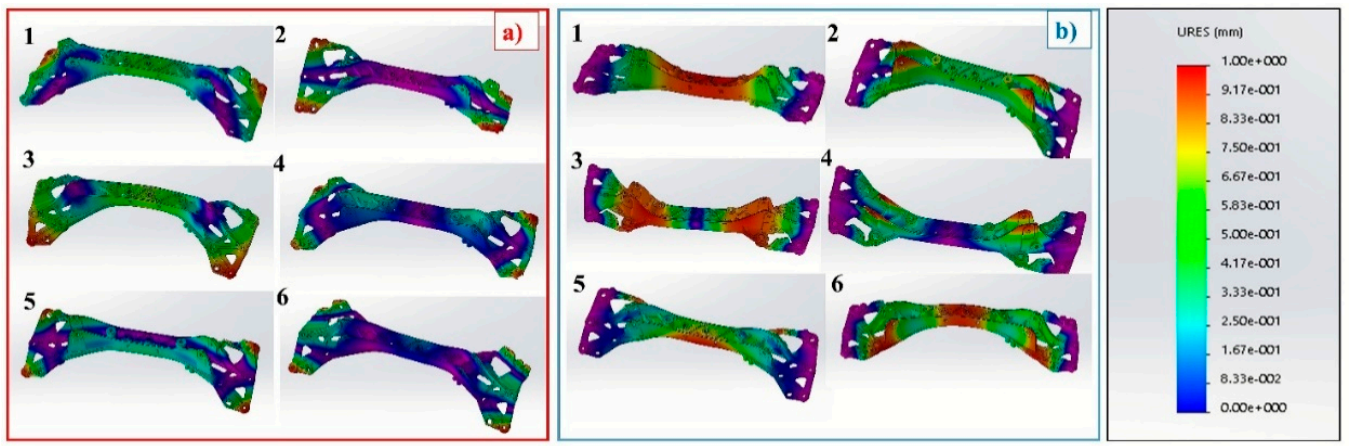

Figure 6. Displacement trend for the first six vibration modes for new geometry: (a) free-free boundary conditions and (b) fixed conditions. 
In particular, Figure 5 refers to the original HPDC geometry, while Figure 6 shows the new one, planned for HPDC with ceramic core application. As is known, the displacement of a structure is a function of the specific vibration mode value; in these simulation results, the component area subjected to the maximum deformability and its consequent flexibility are highlighted. In particular, the red and blue colors represent the maximum and minimum crossbeam displacement, respectively. The values of the first six natural frequencies are reported in Table 5.

Table 5. Natural frequencies values.

\begin{tabular}{ccccc}
\hline First Six Natural Frequencies & \multicolumn{2}{c}{ Original Geometry } & \multicolumn{2}{c}{ New Geometry } \\
\hline $\mathbf{N}^{\circ}$ & Free-Free (Hz) & Fixed (Hz) & Free-Free (Hz) & Fixed (Hz) \\
\hline $\mathbf{1}$ & 226.2 & 251.1 & 330.1 & 264.5 \\
$\mathbf{2}$ & 278.1 & 603.2 & 349.2 & 625.3 \\
$\mathbf{3}$ & 412.1 & 620.3 & 408.2 & 653.5 \\
$\mathbf{4}$ & 632.6 & 810.1 & 677.3 & 905.6 \\
$\mathbf{5}$ & 733.3 & 1044.4 & 745.5 & 1128.1 \\
$\mathbf{6}$ & 882.4 & 1250.4 & 899.3 & 1282.9 \\
\hline
\end{tabular}

The modal analysis results pointed out that the frequencies of the new geometry were higher than the original one, both for free-free and fixed boundary conditions. In general, the boxed solution exhibits an increase of the natural frequencies between $10 \%$ and $15 \%$, compared to the values of the original solution. The greatest increase of the natural frequencies is provided by the modes involving the component's central area, with particular relevance under the torsional modes. The value of torsional frequency for the free-free boundary condition changed from $226.2 \mathrm{~Hz}$ for the original geometry to $349.2 \mathrm{~Hz}$ for the boxed solution, with an increase of about $54.3 \%$. This is an excellent result for this type of component because the first natural frequency values are among the most important design parameters. They have to be over a specific value which depends on vehicle type $[59,60]$.

It is also important to underline that the increase of the component stiffness with the natural frequencies determines also an enhancement of the whole chassis stiffness and, therefore, as is known, vehicle drivability improves, especially on a curve. As regards the extremities of the crossbeam, i.e., the fastening zone, the dynamic behavior of the two components is very similar because this zone is substantially unchanged, due to the interchangeability required by the new component design. The results concerning the buckling analyses are reported in Figures 7 and 8 ; in particular, Figure 7 concerns the original HPDC geometry, while Figure 8 refers to the new one, planned for HPDC with ceramic core application. It is worth noting the component's displacement in correspondence to the specific buckling value coefficient for a load case 1, i.e., only two forces applied to the component; and $\mathrm{b}$ lode case 2, only two moments applied to the component. In Figures 7 and 8 , the red and blue component's areas represented the maximum and minimum displacement, respectively.

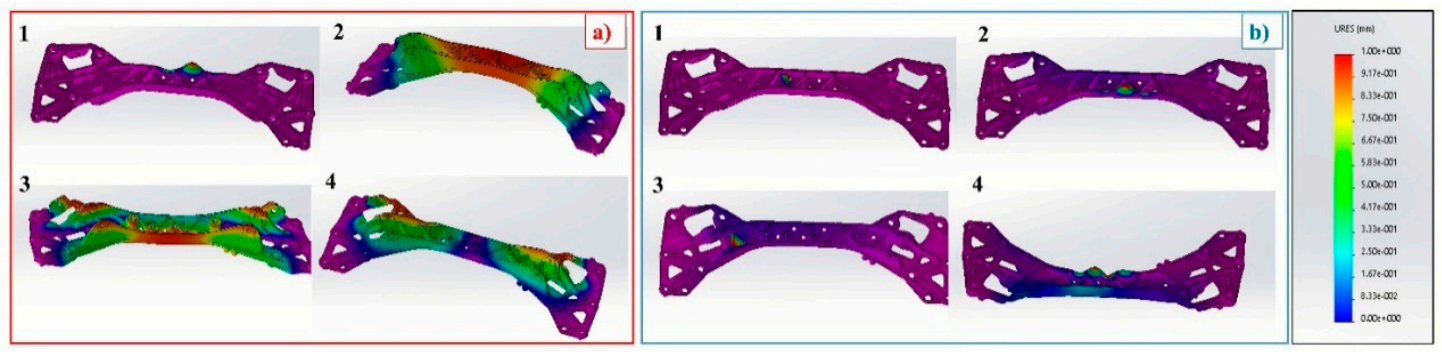

Figure 7. Displacement trend for the first four deformations for original geometry: (a) load case 1 (F); (b) load case $2(\mathrm{M})$. 

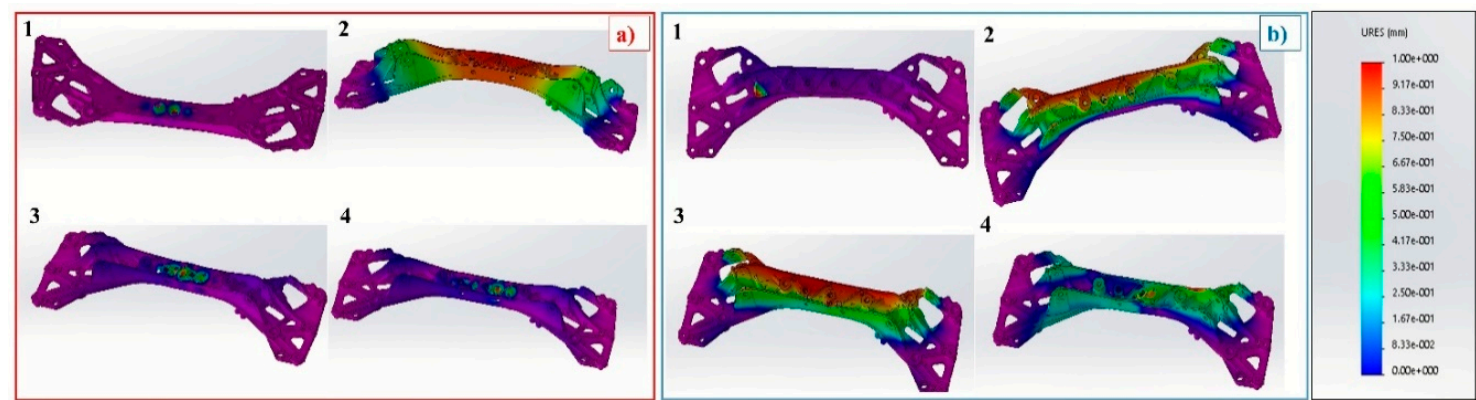

Figure 8. Displacement trend for the first four deformations for new geometry: (a) load case 1 (F);

(b) load case $2(\mathrm{M})$.

Finally, the buckling coefficients are reported in Table 6; these values multiplied by the nominal load (F or M for load case 1 and 2, respectively) represent the load for the elastic buckling phenomena of the structure. From the numerical buckling analyses of both the force and moment applied (corresponding to the supposed loading conditions during the component's lifespan), it is clear that these values are significantly higher in the new solution compared with the original one. This positive result is valid also in the case where the buckling factors values are negative, i.e. when an external load is applied in the opposite direction. This result implies that it is possible to increase the magnitude of the load applied to the component avoiding the buckling's failure; which means that, under load equal condition, the new solution has a bigger safety factor than the original solution. In addition, in the new geometry, it should be noted that the areas close to the holes-implemented to guarantee the alignment of the core in the central area-show the maximum deformability.

Table 6. Load buckling factors for two geometries and for two different external loads.

\begin{tabular}{ccccc}
\hline $\begin{array}{c}\text { Buckling } \\
\text { Coefficients }\end{array}$ & \multicolumn{2}{c}{ Original Geometry } & \multicolumn{2}{c}{ New Geometry } \\
\hline $\mathbf{N}^{\circ}$ & $\begin{array}{c}\text { Buckling Factors } \\
\text { for Load Case 1 (F) }\end{array}$ & $\begin{array}{c}\text { Buckling Factors for } \\
\text { Load Case 2 (M) }\end{array}$ & $\begin{array}{c}\text { Buckling Factors } \\
\text { for Load Case 1 (F) }\end{array}$ & $\begin{array}{c}\text { Buckling Factors for } \\
\text { Load Case 2 (M) }\end{array}$ \\
\hline $\mathbf{1}$ & -1.415 & -0.881 & -1.515 & -1.539 \\
$\mathbf{2}$ & 1.107 & 1.200 & 1.508 & 1.565 \\
$\mathbf{3}$ & 1.742 & 1.254 & 1.706 & 1.931 \\
$\mathbf{4}$ & 1.832 & 1.358 & 1.951 & 1.991 \\
\hline
\end{tabular}

This implies that the new component's geometry can be considerably improved by acting on limited areas and, in particular, the zone around the holes for the core fixing. Overall, it is possible to affirm that the new geometry, planned for HPDC with ceramic core application, has a much higher performance than the original HPDC solution as regards both the dynamic behavior (correlated to the natural frequencies values) and the external loads (correlated to the buckling values).

\subsubsection{Process Simulation}

Standard without-core and ceramic-cored HPDC versions of the casting were simulated in order to understand the difference in filling, improve the runner and gating layout, and to assess core erosion risks and filling-or solidification-related defect formation. Since integrity is mandatory for this part and entrained air bubbles can reduce tensile and fatigue properties, air entrapment was analyzed first.

The filling analysis of both standard and cored versions of the casting shows that only residual amounts of air can be detected in the parts. A threshold visualization was used in order to compare the behavior of the two geometries at the end of filling (Figures 9-11). This is a standard procedure for the analysis of casting simulation. Figure $9 a, b$ shows in blue those mesh cells containing more than $1 \%$ and $3 \%$ of air in volume respectively. The results show that only a few cells in the part contain entrapped air. In addition, those cells are mainly located in the dead ends of the casting and, therefore, air can be 
easily evacuated through a further re-design of the overflows. The situation is very similar in both versions of the casting, but the cored one presents somehow a low increase of air entrapment in the center of the part, just between the two gatings. Also, these points could be improved by evacuating air from the cavity through chill vents or vacuum applications.

Figure $10 \mathrm{a}, \mathrm{b}$ shows the temperature distribution of the alloy at the end of filling in the range between liquidus and solidus temperatures. Some regions of the casting are filled by partially solidified alloy that could potentially lead to the formation of cold joints.

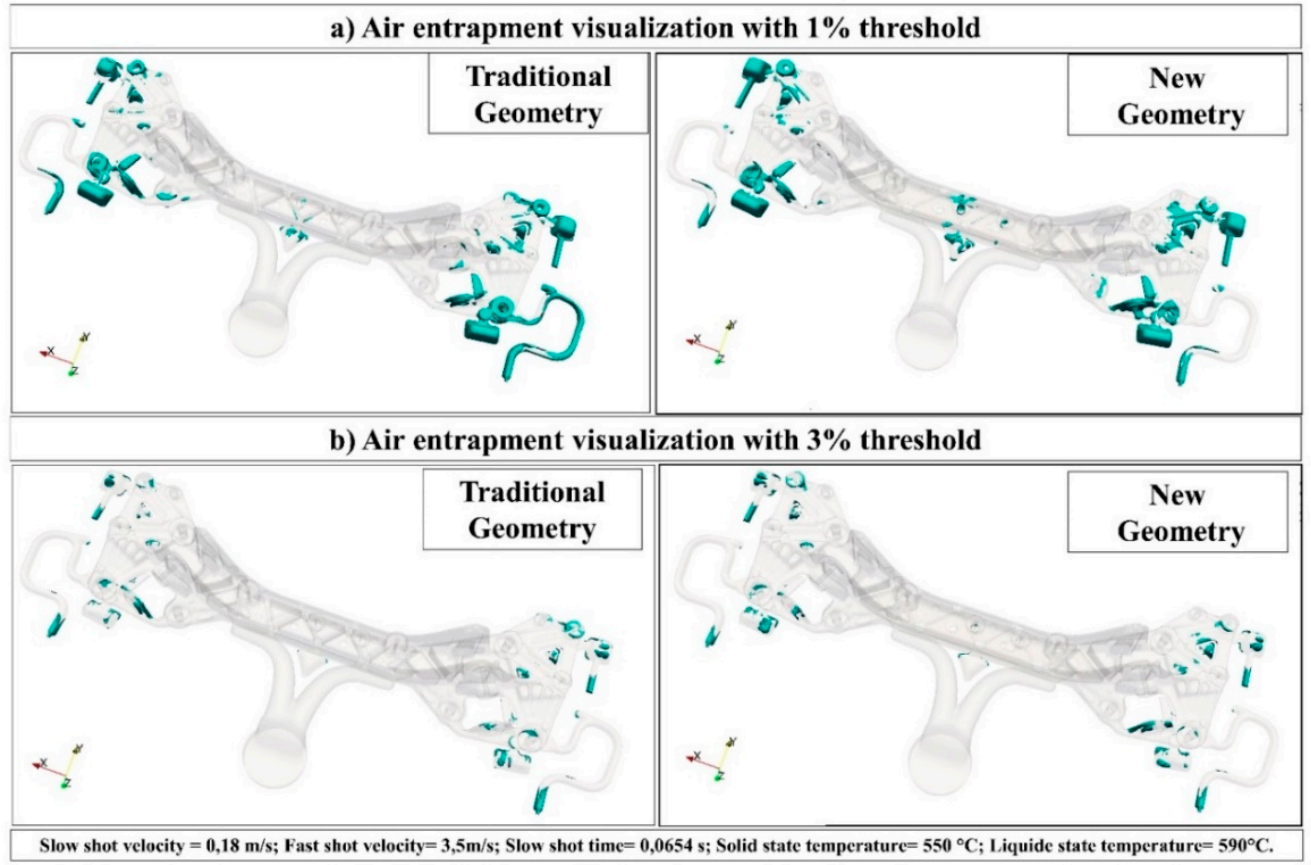

Figure 9. Air entrapment visualization (a) with $1 \%$ threshold and (b) with $3 \%$ threshold for traditional and new geometry.

a) Temperature distribution at the end of filling: liquidus to solidus range

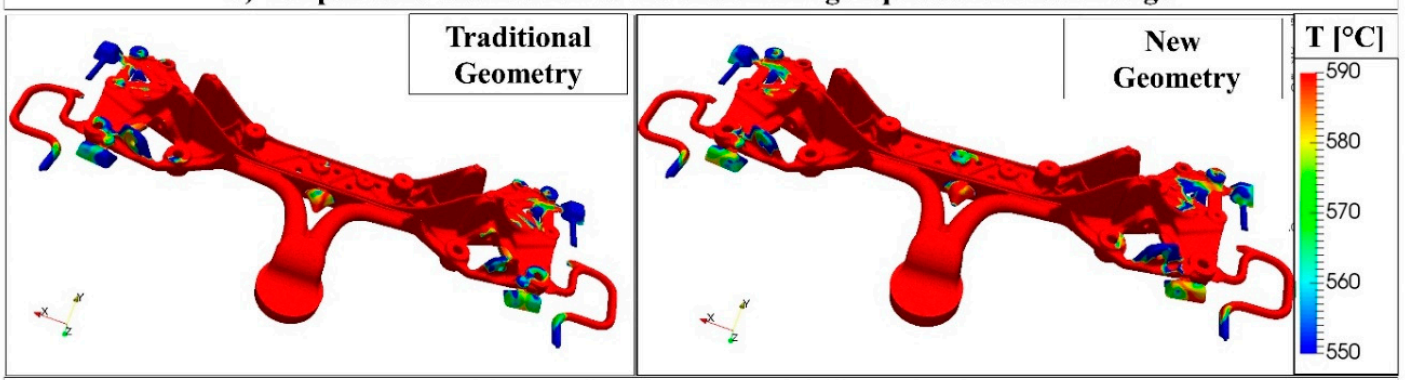

b) Temperature distribution at the end of filling: cold joint locations

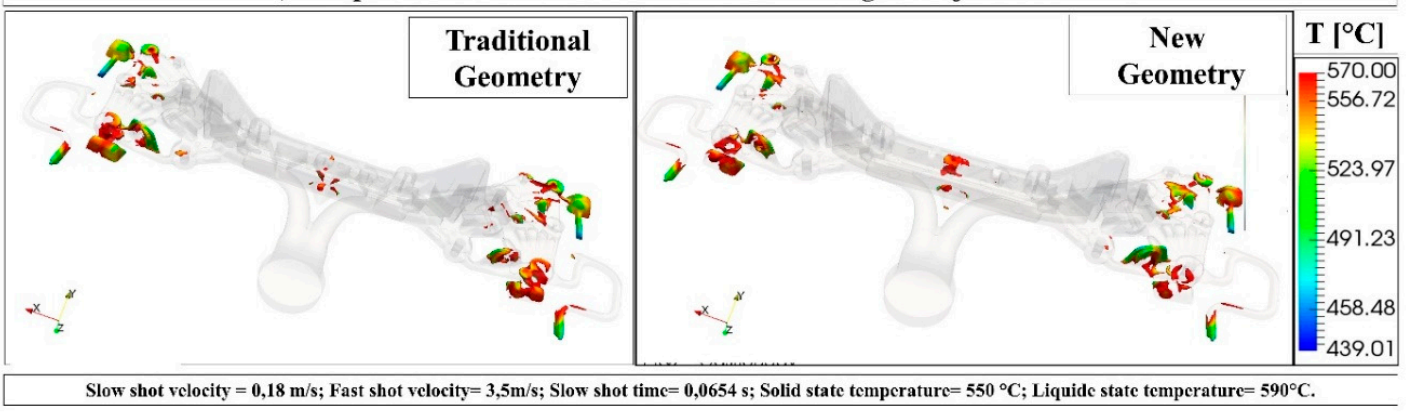

Figure 10. (a) Temperature distribution at the end of filling: liquidus to solidus range; (b) Temperature distribution at the end of filling: cold joint locations. 


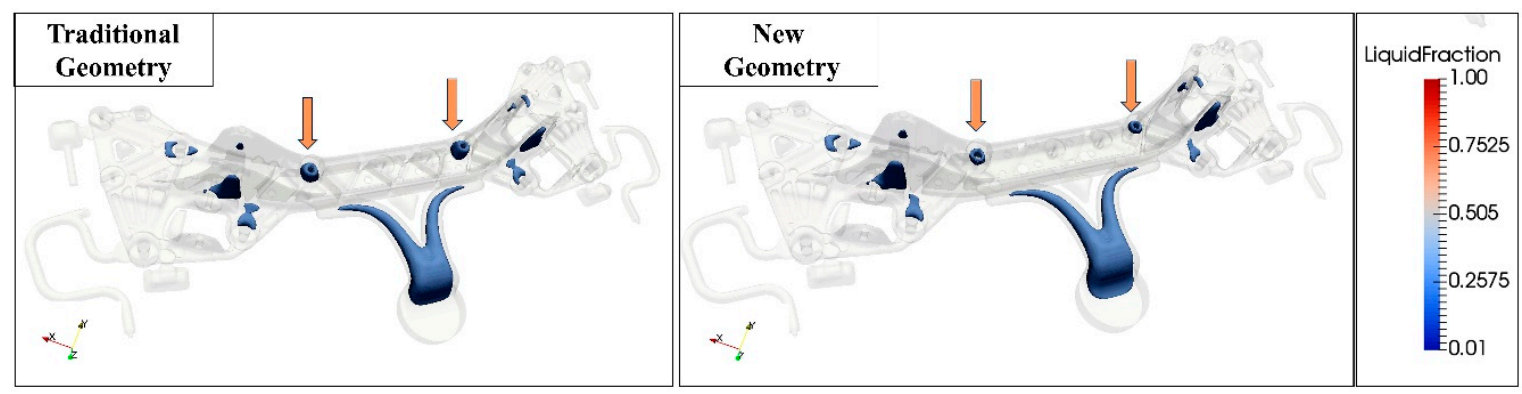

Figure 11. Results of solidification analysis.

In both versions of the casting, most of the potential defects are located in the fixing embossments, far from the ceramic core, which could be an issue to take into account during the assembly of the component. It is worthwhile to note that air entrapment is very similar in both cored and traditional castings, except for the central embossment of the cored one, which shows a pocket of cold metal that should be avoided by improving the process and carrying out a final review of the design. These expedients will allow for further increasing of the soundness of these regions of the casting, which is only slightly affected by the ceramic core introduction into the process.

The solidification analysis (Figure 11) shows some liquid alloy hotspots at the end of the filling that could generate some shrinkage porosity. The results show a slight improvement of the new geometry behavior (cf. the arrows in Figure 11) in comparison with the traditional one. Indeed, the potential risk of shrinkage porosity in the two embossments located on the sides of the ceramic core is lower (smaller liquid fraction pockets) in the new solution, probably due to the reduction in thickness of the casting near this area, resulting in a faster solidification. This could be further improved in both solutions with the introduction of squeeze pins into the die.

The filling simulation process lasts about $0.2 \mathrm{~s}$, whereas the solidification process lasts $8.4 \mathrm{~s}$. These times are in line with traditional HPDC production of components of a similar size. The process simulation was useful to highlight some process and tools improvement (i.e., die, local cooling, squeeze, chill vents, gate injection, etc.). It is worthwhile to note that the defects highlighted in the innovative geometry are very similar to the defects found in the standard geometry.

Finally, the results allow us to affirm that the new HPDC with ceramic core solution is feasible and able to produce complex components with a quality very similar to the traditional process.

\subsection{Material Characterization Results}

\subsubsection{Ceramic Samples}

\section{Density}

The density of the ceramic samples is $1.98 \mathrm{~g} / \mathrm{cm}^{3}$ for sample "a" and $1.92 \mathrm{~g} / \mathrm{cm}^{3}$ for sample " $\mathrm{b}$ " and " $c$ ". No relevant differences were observed between the different materials tested.

\section{Ceramic Decoring}

After preliminary tests, the different sintering temperatures of the ceramic samples have proven not to be relevant parameters. The effectiveness (indicated with $\checkmark$ ) or ineffectiveness (indicated with $\boldsymbol{X}$ ) of the leaching on ceramic and the effect observed on aluminum samples are reported in Table 7 . In particular, these tests pointed out that ceramic samples are etched only by HF solutions, which have a well-known detrimental effect on aluminum. Indeed, aluminum samples burned after the treatment in HF solution. Considering the unpromising leaching results, core removal was carried out on the prototypes using a high pressure water jet. This last operation successfully removed the core and maintained at the same time the component's integrity. These observations are documented by the microscopic analysis reported in the following section. 
Table 7. Ceramic decoring effectiveness $(\boldsymbol{})$ or ineffectiveness $(\boldsymbol{X})$.

\begin{tabular}{ccccccccc}
\hline $\begin{array}{c}\text { Type of Ceramic } \\
\text { Decoring Tested }\end{array}$ & \multicolumn{2}{c}{$\mathrm{HF}$} & \multicolumn{2}{c}{$\mathrm{HNO}_{3}$} & $\mathrm{C}_{6} \mathrm{H}_{8} \mathrm{O}_{7}$ & $\mathrm{CH}_{3} \mathrm{COOH}$ & $\mathrm{C}_{6} \mathrm{H}_{8} \mathrm{O}_{7} / \mathrm{CH}_{3} \mathrm{COOH}$ (1:1) \\
\hline $\begin{array}{c}\text { Acid amount } \\
\text { (water solution) }\end{array}$ & $\mathbf{5} \%$ & $\mathbf{1 0} \%$ & \multicolumn{2}{c}{$65 \%$} & $50 \%$ & $50 \%$ & $50 \%$ & $100 \%$ \\
\hline $\begin{array}{c}\text { Immersion with } \\
\text { ultrasound }\end{array}$ & no & no & no & yes & yes & yes & yes & yes \\
\hline $\mathbf{a}$ & $\checkmark$ & $\checkmark$ & $\boldsymbol{x}$ & $\boldsymbol{x}$ & $\boldsymbol{x}$ & $\boldsymbol{x}$ & $\boldsymbol{x}$ & $\boldsymbol{x}$ \\
\hline $\mathbf{b}$ & $\mathrm{N} / \mathrm{A}$ & $\mathrm{N} / \mathrm{A}$ & $\mathrm{N} / \mathrm{A}$ & $\mathrm{N} / \mathrm{A}$ & $\boldsymbol{x}$ & $\boldsymbol{x}$ & $\boldsymbol{x}$ & $\boldsymbol{x}$ \\
\hline $\mathbf{c}$ & $\mathrm{N} / \mathrm{A}$ & $\mathrm{N} / \mathrm{A}$ & $\mathrm{N} / \mathrm{A}$ & $\mathrm{N} / \mathrm{A}$ & $\boldsymbol{x}$ & $\boldsymbol{x}$ & $\boldsymbol{x}$ & No effect \\
\hline Aluminum & Burned-out & No effect & No effect & No effect & \\
\hline
\end{tabular}

- Three-point bending test

Table 8 reports the average values and standard deviation of Young modulus E (GPa) and flexural strength $\sigma_{\mathrm{f}}(\mathrm{MPa})$ calculated after the three-point bending test on the different ceramic samples. Table 6 shows that both $\mathrm{E}$ and $\sigma_{\mathrm{f}}$ increased as the sintering temperature increased; this effect is particularly remarkable in sample "a". The best match in terms of mechanical properties according to Moschini et al. [50] was found in samples "c- $1110^{\circ} \mathrm{C}^{\text {", }}$, i.e., in the material selected for the production of the hollowed aluminum component.

Table 8. Average values and standard deviation of the Young modulus E (GPa) and flexural strength $\sigma_{\mathrm{f}}(\mathrm{MPa})$.

\begin{tabular}{cccccc}
\hline \multirow{2}{*}{ Samples } & \multirow{2}{*}{ Sintering T $\left({ }^{\circ} \mathbf{C}\right)$} & \multicolumn{2}{c}{ E (GPa) } & \multicolumn{2}{c}{$\sigma_{\mathbf{f}}(\mathbf{M P a})$} \\
\cline { 3 - 6 } & & Avg. & \pm & Avg. & \pm \\
\hline \multirow{2}{*}{$\mathbf{a}$} & 892 & 13.26 & 0.96 & 14.13 & 1.7 \\
& 900 & 13.59 & 1.72 & 14.07 & 1.43 \\
& 908 & 15.45 & 0.83 & 16.28 & 1.91 \\
\hline \multirow{2}{*}{$\mathbf{b}$} & 1075 & 9.2 & 0.76 & 13.02 & 0.92 \\
& 1110 & 10.14 & 0.33 & 13.41 & 0.52 \\
\hline \multirow{2}{*}{$\mathbf{c}$} & 1075 & 12.12 & 1.35 & 17.56 & 1.82 \\
& 1110 & 13.97 & 0.97 & 19.41 & 0.56 \\
\hline
\end{tabular}

\subsubsection{Hollowed Aluminum High Pressure Die Casting Component}

Some hollowed aluminum high pressure die casting prototypes (about 100 pieces) were produced on an IDRA OLS2000 HPDC machine (IDRA group, Brescia, Italy) equipped with automatic ladle, 6-axis robot for ejection and die lubricant spraying. In particular, the prototypes are manufactured using the same casting conditions applied for the process simulations, while the cycle time was approximately $70 \mathrm{~s}$. Next, the ceramic core was removed with a water jet. The crossbeam prototype is shown in Figure 12.

Microstructure

Figure 13 shows one of the transverse sections of a hollowed component in the as-cast condition observed with the optical microscope. In particular, each image is an overview of the entire component's thickness along all its sides, composed by a collage of various micrographs. Figures 14 and 15 show some details at higher magnifications obtained with OM and with SEM equipped with EDS, respectively. 


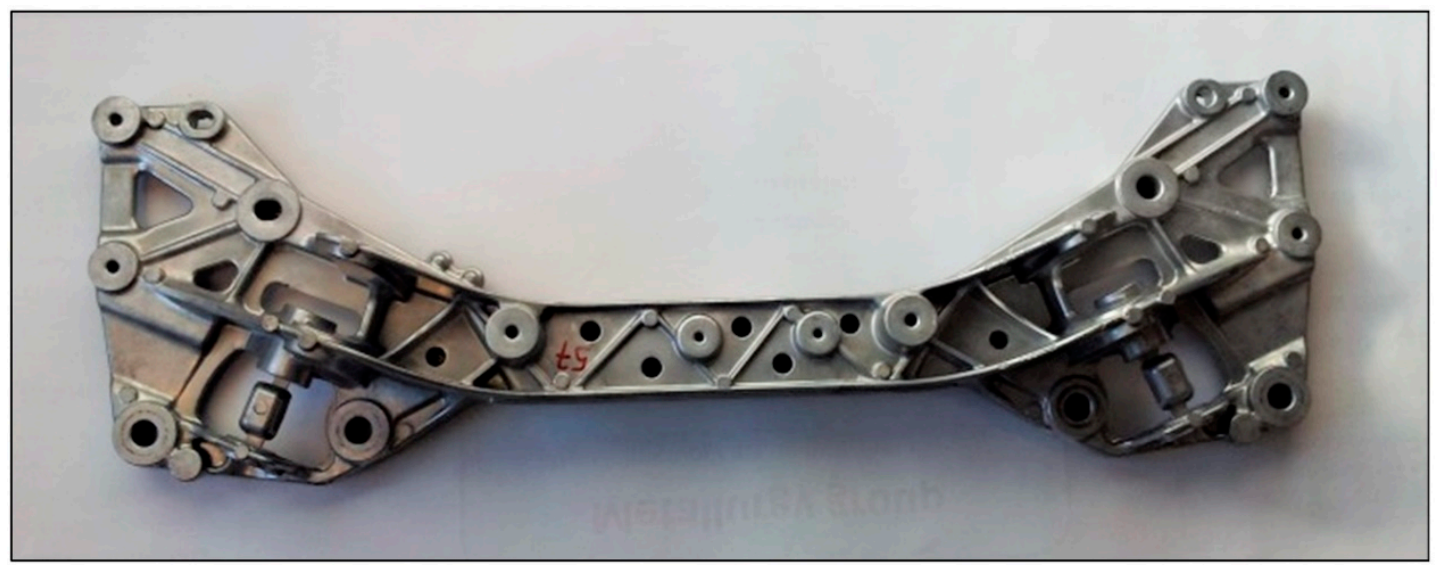

Figure 12. Hollowed aluminum high pressure die casting component.

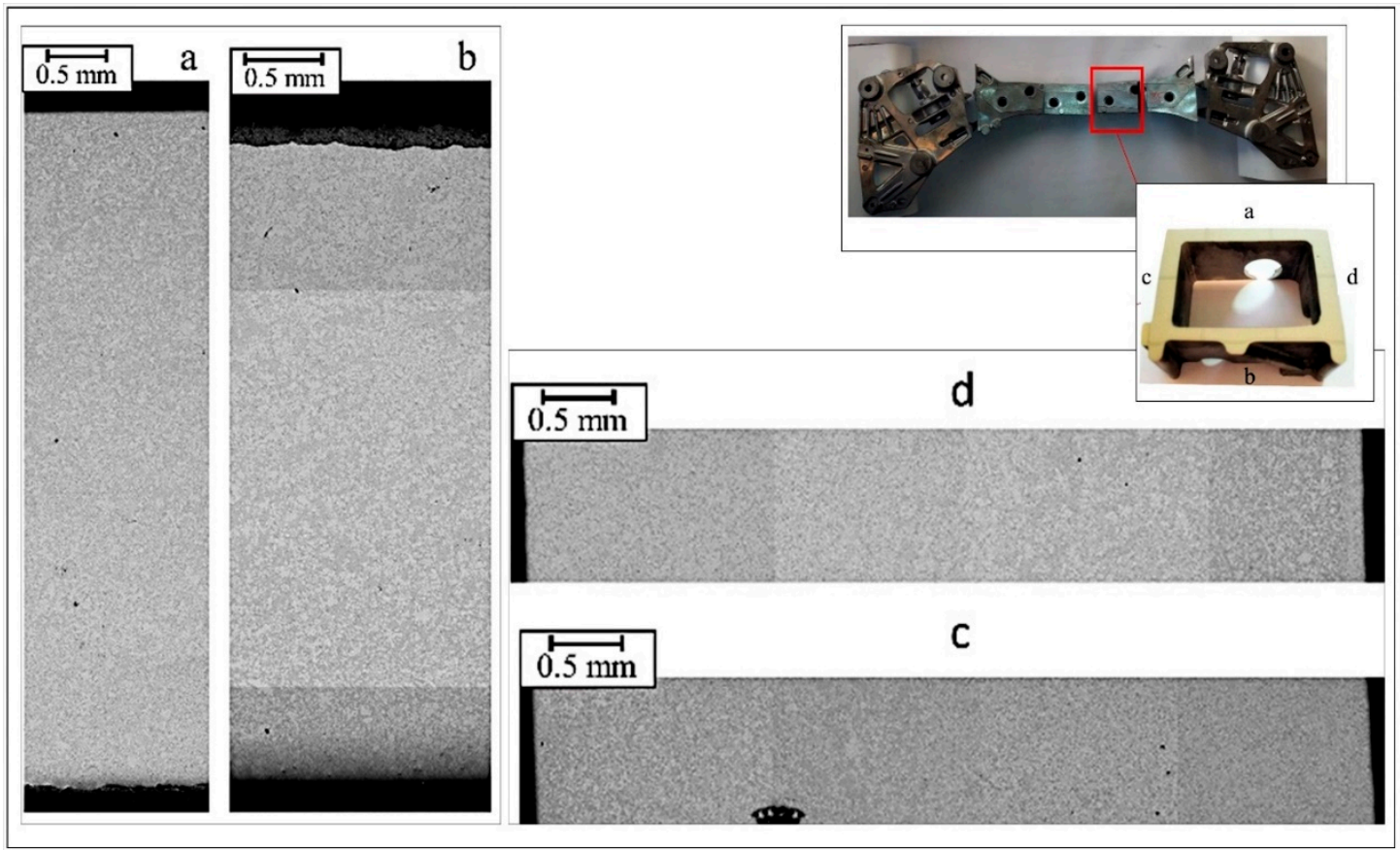

Figure 13. Collage of various micrographs of the transverse sections of the hollowed crossbeam.

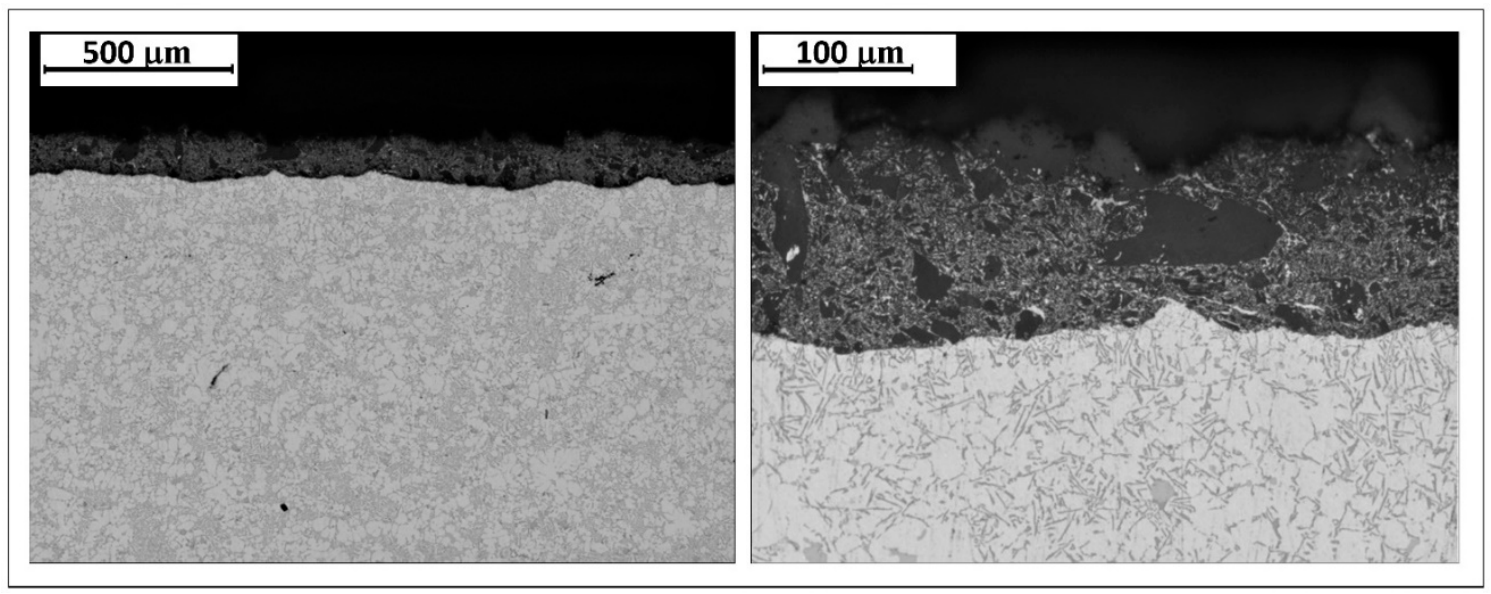

Figure 14. Optical microscope details of the transverse sections of the hollowed crossbeam. 


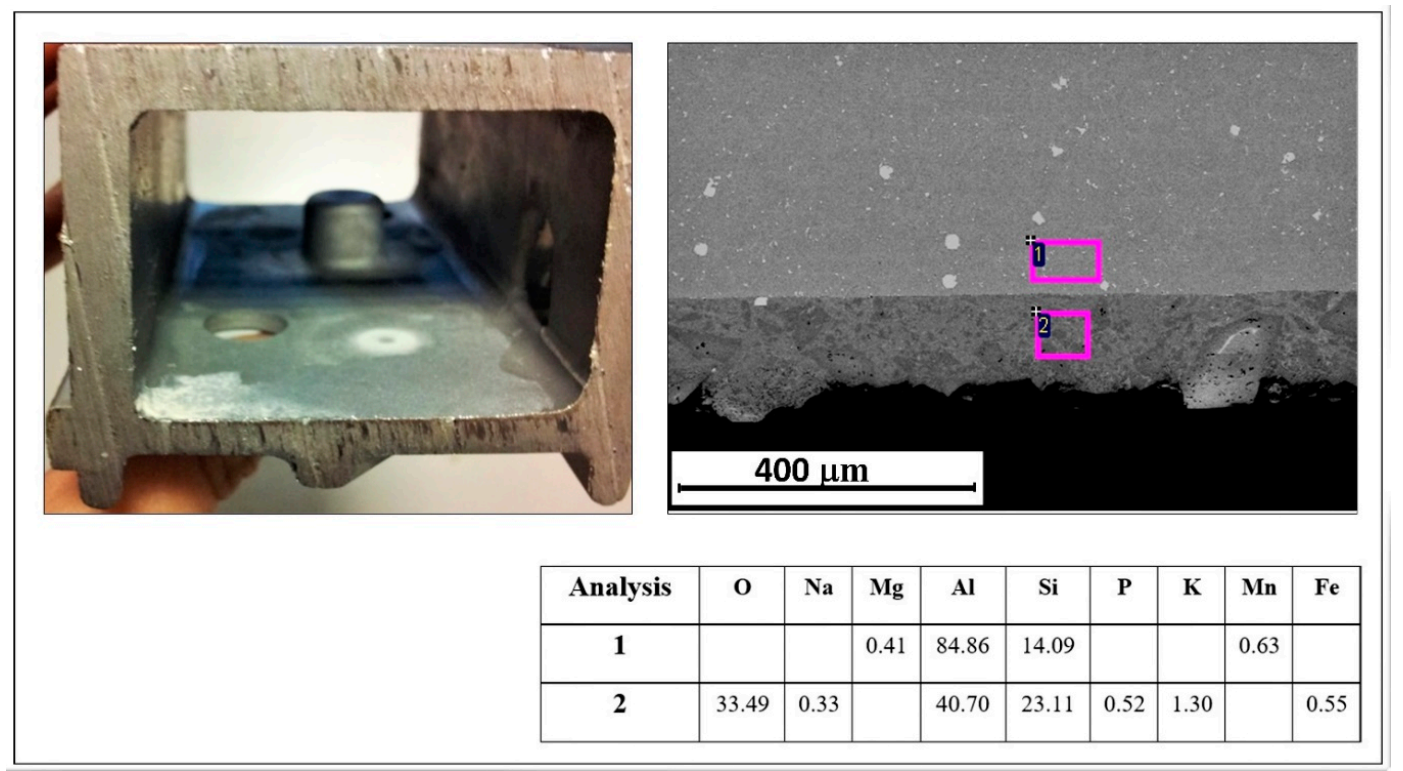

Figure 15. Visual inspection on cermet and SEM image with results of EDS analysis (wt\%).

The OM analyses on the as-cast samples show, for all the samples, a typical microstructure composed of $\alpha$-Al matrix with Al-Si eutectic in the interdendritic space and some intermetallic compounds. In particular, precipitates in EN AC-43500 are usually composed of $\alpha-\mathrm{Al}_{15}(\mathrm{Mn}, \mathrm{Fe})_{3} \mathrm{Si}_{2}$ polyhedral structure [61]. In addition, a cermet compound of about $100 \mu \mathrm{m}$ thickness was observed in some areas of the samples at the interface between aluminum and ceramic core.

Figure 15 shows an example of backscattered SEM appearance of the interface layer between aluminum alloy and cermet. The limits of the instrument with light elements like oxygen are known; therefore, the EDS analysis reported in the figure does not reflect the absolute oxygen amount in the cermet oxides or in the interface, but it is a semiquantitative chemical analysis. The high amount of oxygen observed on the surface of the cavity does not represent the exact value; however, considering also the presence of $\mathrm{Al}, \mathrm{Si}$, and $\mathrm{K}$, it certainly indicates the residual presence of cermet.

This cermet is a ceramic-metal mixture that exhibits high strength and is ideally designed to have the optimal properties of both ceramic, such as high temperature resistance and hardness, and metal, such as the ability to undergo plastic deformation [62-64]. In this work, according to Molina et al. [49], the cermet layer results coherent with aluminum surface and shows no tendency to crush. To prevent this phenomena, a specific coating can be applied on the ceramic cores. It is important to highlight that the cermet has no consequence for the studied application.

\section{Vickers Hardness HV}

Figure 16 shows the variation of the Vickers microhardness HV0.3 as a function of the thickness along the orthogonal section of the component of Figure 13. The position of the cross-section profiles from "a" to " $\mathrm{d}$ " is reported in Figure 13. High variability in the hardness values along the thickness (especially for the "a" and " $\mathrm{d}$ " areas of Figure 13) is noted, probably due to the presence of defects that affect the measurement. Indeed, these values were only considered to assess the alloy's overall mechanical properties. These defects are typical of HPDC process and are not affected by the ceramic core introduction; only the different values of hardness observed at the interface between the ceramic core and the aluminum component are related to the cermet layer. It should be noted that it was not always possible to measure the hardness in correspondence of this composite due to its particular structure. The average overall microHV is comprised in a range between 75 and $90 \mathrm{HV}$, which is typical of similar actual case studies that used the same alloy with the traditional HPDC technology (without ceramic core) [5]. This confirmed that the slight extension of the cermet layer does not affect the microstructure and the mechanical properties in the remaining component section. 


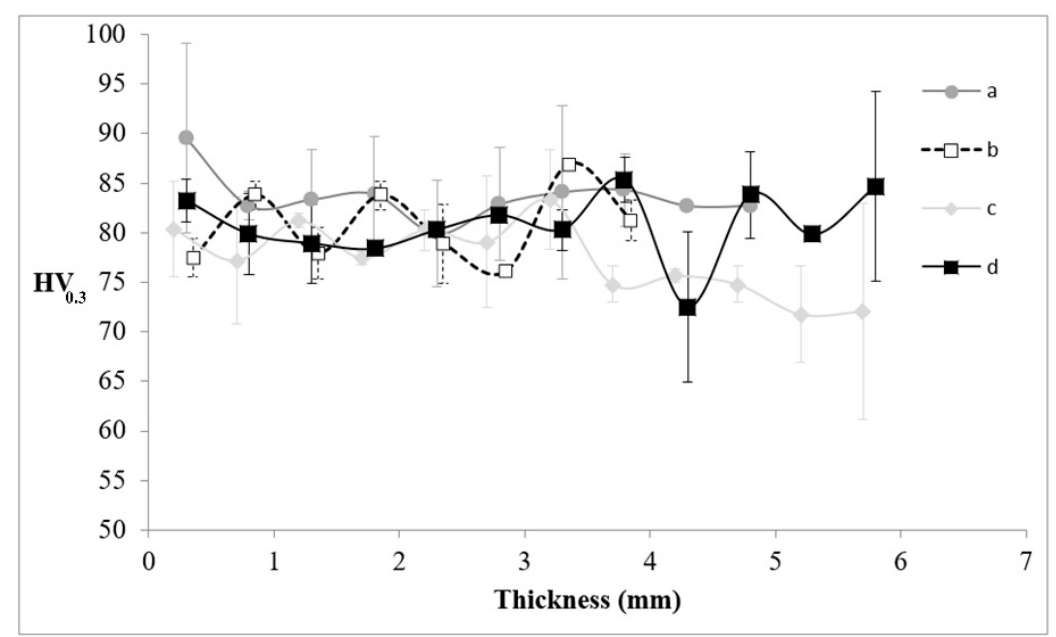

Figure 16. Vickers microhardness HV0.3 variation with respect to the thickness along the transverse section of Figure 13.

\section{Conclusions}

This paper describes the study, the development, and the realization of a new HPDC method with the use of a new ceramic core that allows the production of a lighter and improved safety-relevant automotive component.

In particular, this research investigated the production of an improved aluminum crossbeam for passenger cars with HPDC and innovative lost ceramic cores. The main results in terms of process, structural simulations, and experimental tests can be summarized as follows:

- Despite the thinness of the original component, a slight decrease in weight was achieved thanks to the design modifications applied to the new boxed part.

- The modal analysis results pointed out that the frequencies of the new geometry were higher than those of the original geometry. From the numerical buckling analyses, it is clear that these values are significantly higher in the new solution compared with the original one. Therefore, the new geometry has much higher performance than the original solution, as regards both the dynamic behavior of the component and the external loads that act on the component through the vehicle's chassis.

- The process simulations confirmed that the new HPDC with ceramic core solution is feasible and able to produce complex components with a quality very similar to the traditional process.

- The results of the ceramic experimental characterization allowed for selection of the best match of mechanical properties for the ceramic cores. Approximately 100 hollowed crossbeam prototypes were produced, and the as-cast condition was characterized by means of metallurgical analyses and hardness tests. The results confirm that the actual case study has properties and a microstructure very similar to the component produced with the traditional HPDC technology (without ceramic core). A trace of cermet compound was observed in some areas at the interface between aluminum and ceramic core which is not an issue in this component.

The obtained results demonstrates that HPDC with ceramic lost cores has excellent potential for high production volumes and near-net shape components, with the possibility to produce hollow, thin, and complex parts, contributing to making HPDC competitive with respect to the conventional casting process for the production of automotive hollow parts.

This experimental work has opened the way to future developments that range from the possibility to improve crossbeam lightweighting to the implementation of this technology for other automotive hollow components, such as pillar or different parts of the vehicle chassis. 
Author Contributions: Concept development (provided idea for the research): G.C., D.D., M.F., C.G., L.S., A.P., S.C.; Design (planned the methods to generate the results): G.C., D.D., M.F., A.P., S.C.; Supervision (provided oversight, responsible for organization and implementation): M.F., C.G., A.P.; Data collection/processing (responsible for experiments, patient management, organization, or reporting data): G.C., D.D., L.S., A.P., S.C.; Analysis/interpretation (responsible for statistical analysis, evaluation, and presentation of the results): S.C., G.C.; Literature search (performed the literature search): S.C., G.C.; Writing (responsible for writing a substantive part of the manuscript): S.C., G.C., L.S., A.P.; Critical review (revised manuscript for intellectual content, this does not relate to spelling and grammar checking): G.C., D.D., M.F., C.G., L.S., A.P., S.C.

Funding: This work was supported by Regione Lombardia-MIUR research program "S.A.V.E." [Grant Number ID 30023402].

Acknowledgments: This paper is dedicated to the memory of Renzo Moschini, who recently passed away. He contributed greatly on the study of ceramic core. This work was partly funded by Regione Lombardia-MIUR (research program "S.A.V.E." ID 30023402). The Authors are grateful to Regione Lombardia, Valentina Ferrari and all the project partners for their collaboration.

Conflicts of Interest: The authors declare no conflict of interest.

\section{References}

1. Chindamo, D.; Gadola, M. Reproduction of real-world road profiles on a four-poster rig for indoor vehicle chassis and suspension durability testing. Adv. Mech. Eng. 2017, 9, 1-10. [CrossRef]

2. Chiaberge, M. New Trends and Developments in Automotive Industry; InTech: London, UK, 2011; ISBN 978-953-307-999-8. [CrossRef]

3. Tempelman, E. Multi-Parametric study of the effect of materials substitution on life cycle energy use and waste generation of passenger car structures. Transp. Res. Part D Transp. Environ. 2011, 16, 479-485. [CrossRef]

4. Cecchel, S.; Chindamo, D.; Turrini, E.; Carnevale, C.; Cornacchia, G.; Gadola, M.; Panvini, A.; Volta, M.; Ferrario, D.; Golimbioschi, R. Impact of reduced mass of light commercial vehicles on fuel consumption, CO2 emissions, air quality, and socio-economic costs. Sci. Total Environ. 2018, 613-614, 409-417. [CrossRef] [PubMed]

5. Cecchel, S.; Ferrario, D.; Panvini, A.; Cornacchia, G. Lightweight of a cross beam for commercial vehicles: Development, testing and validation. Mater. Des. 2018, 149, 122-134. [CrossRef]

6. Cecchel, S.; Ferrario, D. Numerical and experimental analysis of a high pressure die casting Aluminum suspension cross beam for light commercial vehicles. La Metallurgia Italiana 2016, 6, 41-44.

7. Morello, L.; Rosti Rossini, L.; Pia, G.; Tonoli, A. The Automotive Body: Volume I: Components Design; Springer: New York, NY, USA, 2001; ISBN 978-94-007-0513-5.

8. Cecchel, S.; Cornacchia, G.; Panvini, A. Cradle-to-Gate Impact Assessment of a High-Pressure Die-Casting Safety-Relevant Automotive Component. JOM 2016, 8, 2443-2448. [CrossRef]

9. Cecchel, S.; Chindamo, D.; Collotta, M.; Cornacchia, G.; Panvini, A.; Tomasoni, G.; Gadola, M. Lightweighting in light commercial vehicles: Cradle-to-grave life cycle assessment of a safety relevant component. Int. J. Life Cycle Assess. 2018, 23, 1-12. [CrossRef]

10. Cecchel, S.; Collotta, M.; Cornacchia, G.; Panvini, A.; Tomasoni, G. A comparative cradle-to gate impact assessment: Primary and secondary aluminum automotive components case. La Metallurgia Italiana 2018, 2, 46-55.

11. Cecchel, S.; Cornacchia, G.; Gelfi, M. Corrosion behavior of primary and secondary AlSi High Pressure Die Casting alloys. Mater. Corros. 2017, 68, 961-969. [CrossRef]

12. Solazzi, L. Applied research for Weight Reduction of an industrial Trailer. FME Trans. 2012, 40, 57-62.

13. Solazzi, L. Wheel rims for industrial vehicles: Comparative and experimental analyses. Int. J. Heavy Veh. Syst. 2011, 18, 214-225. [CrossRef]

14. Hirsch, J. Aluminium in Innovative Light-Weight Car Design. Mater. Trans. 2011, 52, 818-824. [CrossRef]

15. Chindamo, D.; Lenzo, B.; Gadola, M. On the vehicle sideslip angle estimation: A literature review of methods, models and innovations. Appl. Sci. 2018, 8, 355. [CrossRef]

16. Henriksson, F.; Johansen, K. On Material Substitution in Automotive BIWs - From Steel to Aluminum Body Sides. Procedia CIRP 2016, 50, 683-688. [CrossRef]

17. Kelkar, A.; Roth, R.; Clark, J. Automobile Bodies: Can Aluminum Be an Economical Alternative To Steel? JOM 2001, 53, 28-32. 
18. Zhoua, J.; Wana, X.; Lia, Y. Advanced aluminium products and manufacturing technologies applied on vehicles at the EuroCarBody conference. Mater. Proc. 2015, 2, 5015-5022. [CrossRef]

19. Fridlyander, I.N.; Sister, V.G.; Grushko, O.E.; Berstenev, V.V.; Sheveleva, L.M.; Ivanova, L.A. Aluminum alloys: Promising materials in the automotive industry. Met. Sci. Heat Treat. 2002, 44, 365-370. [CrossRef]

20. Dioni, D.; Cecchel, S.; Cornacchia, G.; Faccoli, M.; Panvini, A. Effects of artificial aging conditions on mechanical properties of gravity cast B356 aluminum alloy. Trans. Nonferrous Met. Soc. China 2015, 25, 1035-1042. [CrossRef]

21. Faccoli, M.; Dioni, D.; Cecchel, S.; Cornacchia, G.; Panvini, A. Optimization of heat treatment of gravity cast Sr-modified B356 aluminum alloy. Trans. Nonferrous Met. Soc. China 2017, 27, 1698-1706. [CrossRef]

22. Haracopos, B.; Fisher, T.P. The Technology of Gravity Die Casting; Hart Pub. Co.: Oxford, UK, 1968.

23. ASM. Metals Handbook, 10th ed.; ASM-Metals Park: Geauga, OH, USA, 1990.

24. Campbell, J.; Harding, R.A. Casting Technology; TALAT 2.0 [CD-ROM]; EAA: Bruxelles, Belgium, 2000.

25. Schleg, S.; Kamicki, D.P. Guide to casting and moulding processes. Engineered casting solutions. Technical Articles, 2000.

26. Brown, J.R. Foseco Non-Ferrous Foundryman's Handbook; Elsevier: Oxford, UK, 1999; ISBN 9780080531878.

27. Street, A.C. The Diecasting Book, 2nd ed.; Portcullis Press: London, UK, 1990.

28. Nagendra Parashar, S.; Mittal, R.K. Elements of Manufacturing Processes; PHI learning Pvt. Ltd.: New Delhi, India, 2006.

29. Vinarcik, E.J. High Integrity Die Casting Processes; John Wiley \& Sons: Hoboken, NJ, USA, 2002; ISBN 978-0-471-20131-1.

30. Andresen, W. Die Cast Engineering: A Hydraulic, Thermal, and Mechanical Process; CRC Press: Boca Raton, FL, USA, 2004.

31. Jelínek, P.; Adámková, E.; Mikšovský, F.; Beňo, J. Advances in technology of soluble cores for die castings. Arch. Foundry Eng. 2015, 15, 29-34. [CrossRef]

32. Pierri, D. Lost Core: New Perspectives in Die Casting. Available online: https://www.buhlergroup. $\mathrm{com} /$ northamerica/en/industry-solutions/die-casting/latest-news/details-7797.htm?title= (accessed on 9 February 2019).

33. Czerwinski, F.; Birsan, G.; Benkel, F.; Kasprzak, W.; Walker, M.J.; Smith, J.; Trinowski, D.; Musalem, I. Developing strong core technology for high pressure die casting. Automot. Mater. 2017, 8, 1-11.

34. Rupp, S.; Heppes, F. La rivoluzione nella pressofusione. Tecnico-Industria Fusoria 2017, 4, 72-76.

35. Donahue, R.J.; Degler, M.T. Congruent Melting Salt Alloys for Use as Salt Cores in High Pressure Die Casting. U.S Patent US9527131B1, 25 August 2014.

36. Radadiya, V.A.; Dave, K.G.; Patel, K.R. Design and analysis of salt core for a casting of alluminium alloys. Int. J. Adv. Eng. Res. Dev. 2015, 2, 344-348.

37. Jelinek, P.; Miksovsky, F.; Beoo, J.; Adamkova, E. Development of foundry cores based on inorganic salts. MTAEC9 2013, 47, 689-693.

38. Jelínek, P.; Adámková, E. Lost cores for high-pressure die casting. Arch. Foundry Eng. 2014, 14, $101-104$. [CrossRef]

39. Yaokawa, J.; Miura, D.; Anzai, K.; Yamada, Y.; Yoshii, H. Strength of salt core composed of alkali carbonate and alkali chloride mixtures made by casting technique. Mater. Trans. 2007, 8, 1034-1041. [CrossRef]

40. Yaokawa, J.; Koichi, A.; Yamada, Y.; Yoshii, H. Strength of salt core for die casting. In Proceedings of the International Conference CastExpo '05 NADCA, St. Louis, MO, USA, 16-19 April 2005; NADCA: St. Louis, MO, USA, 2005.

41. Fuchs, B.; Eibisch, H.; Körner, C. Core viability simulation for salt core technology in high-pressure die casting. Int. J. Metalcast. 2013, 7, 39-45. [CrossRef]

42. Fuchs, B.; Körner, C. Mesh resolution consideration for the viability prediction of lost salt cores in the high pressure die casting process. Prog. Comput. Fluid Dyn. 2014, 14, 24-30. [CrossRef]

43. Mizukusa, Y. Casting Apparatus and Casting Method for Producing Cylinder Block. U.S. Patent 5,690,159, 27 August 1996.

44. Ackerman, A.D.; Aula, H.A. Method of Making a Cast Aluminum Based Engine Block. U.S. Patent 4,446,906, 8 May 1984.

45. Brown, W.N.; Robinson, P.M. Soluble Metal Casting Cores Comprising a Water Soluble Salt and a Synthetic Resin. U.S. Patent 364,549, 22 July 1969. 
46. Gibbons, W.A. Core or Filler of Fusible Material for Hollow Vulcanizable Articles. U.S. Patent 1,523,519, 20 January 1925.

47. Foreman, R.W. Mixture and Method for Preparing Casting Cores and Cores Prepared Thereby. U.S. Patent 4,840,219, 20 June 1989.

48. Sakoda, T. Water Soluble Core for Pressure Die Casting and Process for Making the Same. U.S. Patent 3,963,818, 15 June 1976.

49. Molina, R.; Moschini, R. Production of hollow components in high pressure die casting through the use of ceramic lost cores. In Proceedings of the International Conference High Tech Die Casting 2012, Vicenza, Italy, 9-10 April 2012.

50. Moschini, R.; Calzolaro, A.L. Method for Manufacturing Monolithic Hollow Bodies by Means of a Casting or Injection Moulding Process. Patent International Publication No WO 2011/061593 A1, 26 May 2011.

51. Solazzi, L. Innovative Bolted junction with high ductility for circular tubular element. J. Constr. Steel Res. 2015, 112, 175-182. [CrossRef]

52. Mats, G.; Larson, F.B. The Finite Element Method: Theory, Implementation and Applications; Springer: Berlin, Germany, 2010; ISBN 978-3-642-33286-9.

53. Dimitrios, G. Pavlou Essentials of Finite Element Method for Mechanical and Industrial Engineers; Elsevier: Amsterdam, The Netherlands, 2015; ISBN 978-0-12-802386-0.

54. Panvini, A.; Molin, D.; Gislon, C. Dual phase simulation for high pressure die casting: Overview and validation of its capabilities. In Proceedings of the HTDC Conference 2016, AIM, Venice, Italy, 22-23 June 2016.

55. Panvini, A.; Gislon, C. Air entrapment prediction in diecasting through dual phase simulation. In Proceedings of the Die Casting Congress Tabletop 2013, Louisville, KY, USA, 16-18 September 2013.

56. Miller, A. PQ2 and Gating Manual; NADCA: Arlington Heights, IL, USA, 2016.

57. UNI EN 843-1:2007. Advanced Technical Ceramics-Mechanical Properties of Monolithic Ceramics at Room Temperature-Part 1: Determination of Flexural Strength; NSAI: Dublin, Ireland, 2007.

58. UNI EN 843-2:2007. Advanced Technical Ceramics-Mechanical Properties of Monolithic Ceramics at Room Temperature-Part 2: Determination of Young's Modulus, Shear Modulus and Poisson's Ratio; NSAI: Dublin, Ireland, 2007.

59. Smith, J.H. An Introduction to Modern Vehicle Design; Elsevier: Oxford, UK, 2002; ISBN 0750650443.

60. Pacejka, H.B. Tyre and Vehicle Dynamics, 2nd ed.; Butterworth-Heinemann: Oxford, UK, 2006; ISBN 0-7506-6918-7.

61. Franke, R.; Dragulin, D.; Zovi, A.; Casarotto, F. Progress in ductile aluminium high pressure die casting alloys for the automotive industry. La Metallurgia Italiana 2007, 5, 21-26.

62. Tinklepaugh, J.R.; James, R. Cermets; Reinhold Publishing Corporation: New York, NY, USA, 1960; ASIN B0007E6FO4.

63. Hanaor, D.A.H.; Hu, L.; Kan, W.H.; Proust, G.; Foley, M.; Karaman, I.; Radovic, M. Compressive performance and crack propagation in Al alloy/Ti2AlC composites. Mater. Sci. Eng. 2016, 72, 247-256. [CrossRef]

64. Bhattacharya, A.K.; Petrovic, J.J. Ductile phase toughening and R-curve behaviour in a B4C-AI cermet. J. Mater. Sci. 1992, 27, 2205-2210. [CrossRef]

(C) 2019 by the authors. Licensee MDPI, Basel, Switzerland. This article is an open access article distributed under the terms and conditions of the Creative Commons Attribution (CC BY) license (http://creativecommons.org/licenses/by/4.0/). 